\title{
VIRTUALITY IN THE SPHERE OF ECONOMICS*
}

\author{
Vili Lehdonvirta
}

\section{Abstract}

This chapter examines virtuality and reality in the context of economic affairs. Digital objects and currencies found in online game worlds and digital environments are considered play and make-believe, and are branded as "virtual" to distinguish them from the serious world of "real" consumption and economics. However, virtual goods are increasingly bought and sold for real money, and the value of such trade now reaches several billion US dollars per year. This encroachment of the "virtual" into the "real" serves as an occasion for a critical reevaluation of supposed economic realities. It turns out that the value of "real" goods and currencies is often just as subjective as that of their supposedly virtual counterparts. The real-virtual dichotomy in economic affairs is a social construct, and sometimes things are labeled "virtual" simply to marginalize them. As the "real" economy looks increasingly vulnerable, such categorizations may shift.

Keywords: online games, virtual goods, virtual currency, economic crisis, value, subjectivity

\footnotetext{
* This is a preprint version of the following book chapter:

Lehdonvirta, V. (2013) Virtuality in the sphere of economics. In: Grimshaw, M. (ed.) The Oxford Handbook of Virtuality, Oxford: Oxford University Press, chapter 31.
} 


\section{Introduction: Russia's Post-Soviet Virtual Economy}

In 1990s post-Soviet Russia, enterprises, government branches, and households were engaged in a curious system of commerce that was different from the Soviet planned economy, but also unlike the Western free-market system that reformers wanted to instate (Gaddy and Ickes 1998; 2002). Its characterizing feature was that enterprises paid much of their dues to each other, to their workers, and to the tax collectors in kind, and that everyone who received such payments accepted them at a higher face value than what the market price of such goods would have been. In particular, manufacturing companies were able to tap into Russia's massive natural resources at rates far below world market prices by paying with their own overpriced products instead of currency. This effective subsidy allowed Russia's unreformed manufacturing sector to survive the sudden exposure to global competition. But to those who looked at accounting books as if they represented world market prices, it created an illusion that Russia's economy was much larger than it in reality was. When Western economists understood what was happening, they branded the system a "virtual economy" of "virtual revenues" generated through "virtual prices" (Gaddy and Ickes 2002).

The most common use of the term "virtual" in economic literature is technical: it is used in models to indicate a theoretical construct that is not intended to have an empirical counterpart. But in those rare cases where it is used to describe an empirical concept, I argue that it has three important characteristics that the case of Russia's post-Soviet economy illustrates well. First, calling something a "virtual" entity is intended to indicate that the entity in question has the appearance or some of the usual characteristics of its kind, but is nevertheless not the real thing. In other words, a virtual thing is an illusion, a pretense, or even an outright fraud. Second, the "virtuality" of an entity is always established in relation to something else that represents the "real." In the case of Russia's post-Soviet economy, the "real" prices that Western economists had in mind were world market prices, and the "real" economy was a Western-style market economy. These two characteristics of the term lead to a third and arguably the most important characteristic, which I will illustrate below.

Although Russia's post-Soviet system was notoriously inefficient and it is not my intention to defend it here, the system also had its proponents. The in-kind payments in effect meant that national gas and oil income was being distributed to the people as a form of social welfare, through wages in the enterprise sector. This type of social welfare was not part of the free-market reformers' agenda, as they wanted to privatize Russia's natural resources. By calling the prevailing system a "virtual" economy, the reformers could promote the notion that the system was inferior and had to be replaced by one that qualified as a "real" economy. For some, the "real" system would be better, but for others, it would be worse - it was a political struggle, and "virtual" was a political word. In other words, the third characteristic of the term "virtual" is that it is a loaded word that tends to be used as a rhetorical device to persuade readers toward a particular viewpoint. 
The sphere of economics extends from scholarly economic debates to public discourse concerning economic affairs. In the recent years of economic tumult, this distinction has become increasingly permeable. In the remainder of this chapter, I examine virtuality in the sphere of economics through two contemporary phenomena: virtual consumption and virtual money. Both originally earned the addition "virtual" to their name through associations with information technology and virtual worlds, which are multiuser environments that in turn probably owe their label to the concept of virtual reality. According to the New Oxford American Dictionary, the adjective "virtual" in computing means "not physically existing as such but made by software to appear to do so." Mundane examples include virtual memory and virtual computer. In information technology, this adjective is almost purely descriptive with little value content. But it will be seen that in discourse on economic affairs, it acquires the three characteristics that were identified above in connection with Russia's virtual economy. In the concluding section, I consider what the "marginalization by virtualization" of the two phenomena under scrutiny suggests about the realities of our economy.

\section{Virtual Consumption of Digital Goods}

Digital games and online communities have for a long time included features that simulate economic activity. For example, Habitat, opened in 1985, was an early pioneer of digital environments. It used two-dimensional graphics to represent spaces such as home, hotel, and arcade, where cartoon-style characters controlled by users could talk and interact. The landscape was scattered with vending machines from which users could purchase virtual items ranging from weapons to furniture. Purchases were paid with a currency called Tokens, which was distributed to the users for free (Dibbell 1998, 172). This was a kind of "consumption play": an activity that mimics actual consumption without really being so (Lehdonvirta, Wilska, and Johnson 2009). So-called massively multiplayer online games (MMOs) have since taken consumption play much further: they feature simulations of whole economies, complete with processes of extraction, manufacturing, trade, and consumption. Such simulations are clearly "virtual economies" in the sense of "not physically existing as such but made by software to appear to do so," and that is indeed the name applied to them in popular as well as academic literature (Castronova 2006). The simulated goods that circulate in these economies are called "virtual goods."

The status of virtual economies as simulations began to be questioned, however, when players started to exchange virtual goods for real money. Around 1999, some MMO players started to put their game goods on auction in the recently launched ecommerce sites like eBay (Castronova 2006; Huhh 2008). Perhaps surprisingly, they soon received bids from other players. When an auction was completed, payment was carried out using ordinary means, such as check or money order. The two players then met up in the game and the seller handed the auctioned object to the buyer. This way, an exchange value measured in US dollars or Korean won could soon be observed for virtual goods ranging from characters to gold nuggets. The biggest publicly reported player-to-player trade is the 2007 sale of a character in the online game World of Warcraft for approximately 7,000 euros (Jimenez 2007). 
As trade volumes increased, what started as a player-to-player phenomenon soon attracted commercial interest. Professional players, known as "gold farmers," began to play the games for profit rather than pleasure, harvesting massive amounts of game assets and selling them to wealthier players on online markets. By mid-2000s, this activity had grown into a whole industry that was estimated to employ as many as 100,000 game laborers in digitally connected low-income countries such as China (Lehdonvirta and Ernkvist 2011). Virtual goods are now also among the most soughtafter commodities among cybercriminals (Krebs 2009). Criminals hack into players' game accounts, steal the enclosed virtual items and currencies, and sell them on electronic marketplaces for a profit.

Before long, game publishers and online community operators took note of this phenomenon. Instead of charging users a subscription fee or showing advertisements, they realized that they could generate revenues by selling virtual items to their users. This business model first became popular in Korea, China, and Japan (Nojima 2008; Wi 2009; So and Westland 2010), and around 2009, broke into mainstream Western online business (Lehdonvirta and Ernkvist 2011). For example, American game developer Zynga makes relatively simple simulation and nurturing games that anyone can play for free on Facebook. Their hit game Farmville at best claimed over 90 million active players. Those players who wish to advance faster in the game's virtual economy can buy items such as virtual tractors and tractor fuel. So many players do that Zynga earned $\$ 1.14$ billion from its games in 2011. In total, approximately $\$ 7$ billion worth of virtual items and currencies were estimated sold by publishers in 2010 (Lehdonvirta and Ernkvist 2011). More virtual tractors were sold in a day than real tractors in a year. Most recently, virtual goods have become a highly popular way to spend money in mobile and tablet games.

Some people reacted with hostility toward this new type of consumption. In Finland, opinions in the media and public discourse concerning spending on game goods were rather negative during most of the 2000s (Lehdonvirta 2009a). Many parents of children and teenagers who were purchasing game items saw it as another unnecessary expense and fought actively against it. Consider the following quotes, taken from readers' comments on an article related to virtual consumption published in the online version of the newspaper Helsingin Sanomat on March 23, 2008 (quoted in Lehdonvirta 2009a, 11-12):

It is completely insane to pay for something that in reality does not exist.

Consider what better and real reality you could have gotten for that money.

It's pointless to pay for virtual stuff when it could just as well be free.

[Selling virtual goods] represents taking advantage of children both economically and psychologically.

Previously you couldn't abuse children in business like this. It's incredible that Finland is a major player in this immoral practice. I wonder how many Finns' income depends on getting children to consume the most foolish things! 
The comments above exemplify a number of common views held toward virtual consumption that question the rationality of spending money on virtual goods. Virtual goods are typically seen as illusory, imaginary, unreal, or even nonexistent. They are contrasted with "real" goods, which are rational, useful, and valuable. Something real is better than something virtual. According to this view, virtual goods are not worth anything, either because of their ephemeral nature, or because they are digital, and digital image flows are reproducible without cost. Spending real money on virtual goods is therefore considered irrational.

It is probably safe to say that the above views, highly critical of virtual consumption, are often arrived at without substantial study or experience of the actual practices of virtual consumption. They are outsider impressions. The insiders, the virtual consumers themselves, obviously have substantial experience and embodied knowledge regarding the actual practices as well as the meanings and motivations behind virtual consumption. But they lack the motivation and perhaps also the capability and analytical distance to express these in a form that could be digested by parents, regulators, and mainstream media, and thus fail to contribute to a debate on virtual consumption.

What is at stake in this debate? From a societal perspective, the spending of real money on virtual goods, as an emerging phenomenon, does not have an established position in society. It could be characterized as "gaming," which carries with it certain meanings and places it in a certain ethical frame: recreational spending, leisure, but also frivolousness, distraction, and even addiction. It could also be characterized as a form of "online shopping": economic activity, conventional, legal, but also hedonistic and subject to a different set of ethical concerns. And it could also be characterized as "exploitation," as above.

The way in which parents, regulators, and other authorities conceptualize (or fail to conceptualize) virtual consumption has very practical implications for the people involved, individuals as well as companies (Lehdonvirta 2009a). For example, whether society sees virtual consumption as something legitimate and desirable or something irrational and subversive will greatly shape its uptake as an economic activity. In Korea, the National Assembly has passed a law that makes certain types of real-money trading of virtual goods illegal (Lehdonvirta and Virtanen 2010). In Finland, complaints from parents led the consumer ombudsman, a public official, to call for negotiations with Sulake, a company operating an online hangout popular among teenagers (Lehdonvirta and Virtanen 2010). Consequently, Sulake now imposes a weekly limit on the amount of money its customers can spend on virtual goods. The limit varies from country to country. According to Sulake, the spending cap is set to correspond approximately with the local price of a cinema ticket (Lehdonvirta and Virtanen 2010). Purchases of cinema tickets, sweets, clothes, or indeed anything else that young people spend their money on are not capped in this way - the spending cap is unprecedented. Greg Lastowka's chapter in this book (chapter 29) contains more examples of legal struggles related to virtual goods.

Research on virtual consumption does not support most of the negative interpretations put forward in the public discourse. First, the position that spending real money on 
virtual goods is insane because the goods "do not really exist" is untenable (Lehdonvirta 2009a). Virtual goods are not figments of imagination: they are physically stored in database servers and are visible and can be manipulated through computer interfaces. In this sense, they are even more tangible than many of the more conventional ways of spending money, like watching a movie or listening to music. Virtual goods clearly do exist, and in this sense are quite "real."

Second, virtual goods are not useless as goods, even though they are "virtual" in the sense of being implemented in software. Empirical studies suggest that consumers use virtual goods in digital media for many of the same purposes as they use material goods in physical environments: to seek fulfillment of needs, real or imagined (Martin 2008; Lehdonvirta 2009a; 2009b), to construct and communicate social distinctions, bonds, and identity positions (Martin 2008; Lehdonvirta 2009a; Lehdonvirta, Wilska, and Johnson 2009), and to stimulate and pursue hedonistic fantasies (Denegri-Knott and Molesworth 2010). In other words, although virtual goods obviously cannot offer nutrition or shelter to the body, they are quite capable of being used in the majority of roles that commodities are used in in a consumer society. Chapters 17, 18, and 19 of this book (Albright and Simmens; Stenslie; Geraci) show how behaviors like dating, sex, and religion are acted out over digital media; it should come as no surprise that consumerism can be acted out over digital media also.

Still, those who assert that virtual goods are not "real" are probably not meaning it in the ontological sense, but rather in a more practical and colloquial sense. Virtual goods are digital and limited to digital spaces only. Even if we accept that virtual goods are technically part of the same reality as everything else, it can be argued that in practice they are not present in most situations or their impact is so insubstantial that they are more like fantasy than actual goods. Turn the computer off, and their thin link to reality disappears. Thus virtual goods "do not really exist" in the way the living room sofa does (Lehdonvirta 2009a).

Studies of media use show that the proportion of time spent with digital media continues to increase even in countries where it is already high (e.g., Räsänen 2008). For people who interact mostly in the digital world, it is the living room sofa that lacks presence and impact in most situations. If those are the measures of reality, it is the sofa that must be termed "unreal" in such a case. Furthermore, the digital world is increasingly penetrating into face-to-face social situations. Mobile devices, public display screens, and, in the near future, wearable computing and augmented reality applications make it possible for virtual objects to have presence and impact in social situations of the material world (Montola and Stenros 2009; Nojima 2008). For example, location-based service Foursquare creates a virtual layer of collectible badges on top of urban gathering places, and millions of participants compete to obtain them. A particular virtual badge might afford its owner not only social status among peers, but tangible economic benefits at the restaurant or establishment in question.

From an economic perspective, the strongest argument in support of the "reality" of virtual consumption is that businesses based on selling virtual goods contribute to the gross domestic product (GDP) in the very same way as their more material 
counterparts. The more people spend on virtual goods, the more virtual goods business will contribute value to the economy. The same applies to any goods, from furniture to cinema tickets. Virtual goods are perhaps more ephemeral than many material goods, because they might, for example, disappear suddenly if the operator goes out of business. But in today's economy, economic prosperity is not measured by the amount of durable goods hoarded in vaults, but by GDP: the total spending on final goods and services produced in a country (Burda and Wyplosz 1997, 21). Thus lack of durability can even be a virtue to the national economy, if it leads to repeated spending.

Given that virtual goods are in practice "real"- they are used for largely the same purposes as other consumer goods, and they contribute to the national economy just like any other goods - what is at the root of the assertions to the contrary? Why are the people quoted in the examples above attempting to marginalize digital item sales by positing a strong boundary between "real" and "virtual" consumption? In part, this is probably explained by the inertia of consumption-related social norms. The categories of consumption that are considered necessary and permissible, and those that are considered a luxury and a vice, change slowly over time (Belk 2004, 71-72). For example, over the past two decades, computers and mobile phones have undergone a classificatory shift in rich countries, from unnecessary or pretentious luxury to basic necessity. This suggests that more recently emerged forms of technology consumption, such as virtual items, simply take time to become acceptable, regardless of their harms or benefits.

There may also be a deeper reason for the "marginalization by virtualization" of digital item sales. Critical thinkers such as Baudrillard (2002) and Lury (1996) suggest that we live in a consumer culture where the primary means through which people pursue meaning in their lives is through the purchase and accumulation of goods. Virtual consumption is such a strikingly naked example of this culture that it perhaps provokes people to realize the futility of their own pursuits. Decorating a physical home with the latest interior design is after all little more than an expensive and environmentally destructive sibling of decorating a virtual playhouse with which to impress friends. Consumers unwilling to let go of the fantasy that their material consumption games are somehow more meaningful and serious may thus find it necessary to marginalize virtual consumption lest it cause uncomfortable cognitive dissonance.

\section{Virtual Money, Real Money?}

Besides virtual goods, the Internet has also seen a huge proliferation of so-called "virtual currencies" during the past decade (Lehdonvirta and Ernkvist 2011; Lehdonvirta 2009a). Many of these currencies are simply play money that is used in online games to trade game items. Others are used in the manner of arcade tokens to facilitate purchases of digital goods: the consumer buys the currency from the vendor and then spends it on the vendor's or the vendor's partners' products. Facebook Credits are an example of such token money. Still others are digital currencies intended to be used in general online commerce between any willing parties. Bitcoin is the most prominent example of such a currency. In some cases, the distinctions are 
blurred, and a currency that was originally intended for a more limited purpose becomes a general online currency. An example of this is Q Coin, a token money issued by a company called Tencent that became an almost general online payment system in China, until the People's Bank of China issued a proclamation prohibiting the use of virtual currencies in the trade of physical goods.

What all of these currencies have in common is that they are termed "virtual money" in media and popular discourse. The "real money" implied by this terminology is national currencies like the US dollar and the euro. So what is the essential difference between "virtual money" and "real money"? The difference is not that one is digital and the other is not. Some virtual currencies come in the form of physical cards or tokens, and most dollars and euros today exist only in the form of digital records in banks' accounting systems. To analyze the real difference, it is necessary to first clarify what real money is. In the midst of economic crises, fluctuating exchange rates and unpredictable interest rates, we hear a lot of talk about money and finance in the media, yet very few people today could say what money actually is.

Economists generally identify three purposes for money: it is (1) a medium of exchange, (2) a store of value, and (3) a unit of account (Mankiw 2009, 80-81). Money is defined through these purposes: any object or record that is used for these purposes is and can be called money (80-81). Let us clarify these purposes below.

If two people wish to exchange goods via barter, the problem is that they both have to have something that the other party desires for the exchange to be possible. Failing that, they have to find a third person that is willing to accept something from the first person in exchange for something desired by the second person. Needless to say, this makes trade difficult. The problem can be avoided by using a medium of exchange: a universal commodity that everyone accepts as payment, either because they need it directly, or because they know that they can always later exchange it to something that they need. In ancient Egypt, gold was used for this purpose, whereas in Babylonia, silver and grain were used. In Iron Age Finland, squirrel pelts were the favored medium of exchange.

A store of value is simply something that is used to preserve value across time. An apple farmer is rich in apples after harvest, but the apples will perish in a few months. To have something to pay with even months after harvest, the farmer must exchange the apples to something more durable. Historically, precious metals have been popular stores of value.

A unit of account is a measuring stick in which value is measured. For example, prices and debts can be expressed in euros or ounces of gold. Sometimes the currency used as the medium of exchange is different from the unit of account. For example, the euro was adopted as an accounting unit in governments and banks before actual euro coins and notes were released into circulation. But in general, one region tends to have one main money that is used for all the three purposes.

Now that we have defined real money, how does virtual money differ from it? Consider the most frivolous example: virtual gold coins used inside an online game. 
They are used as a medium of exchange to facilitate transactions between players. If the game has perishable goods, players will certainly also use the gold coins as a store of value. And it goes without saying that the gold coins are used as a measure of value when expressing prices of goods and debts between players. The perhaps surprising conclusion seems to be that virtual money does not differ in any way from "real" money. There is simply money.

In practice, the difference between those currencies that tend to be called "virtual money" and those that are afforded the status of "real money" is in the size of their currency areas. Economists usually understand a currency area as a geographic area within which a particular currency can be used to pay for goods and services (Mankiw 2009, 362-363). But an equivalent and more flexible definition is that a currency area is the total set of goods and services payable with a given currency. Virtual gold coins in an online game can for the most part only pay for virtual goods inside the game, and perhaps also for some services provided by dedicated players of the game. A national currency can usually pay for a much larger variety of goods and services, although it probably cannot be used to pay for the aforementioned virtual goods. Differences in the sizes of the currency areas are only differences of degree, not of any fundamental quality. In some cases a virtual currency may even have a currency area that rivals small national currencies in size, as perhaps was the case with China's Q Coin. When the People's Bank took action against this digital currency, it was not because of its virtuality, but because of its reality, its real economic influence. Still, in rhetoric, the bank emphasized that virtual currencies should not be confused with real economic affairs, marginalizing the Q Coin.

A reader might intuitively suggest that there is nevertheless one fundamental difference between real and virtual money: that real money is more trustworthy than virtual money. After all, real money is issued by governments and banks, whereas virtual currencies are typically issued by Internet companies and other smaller private organizations. To analyze this claim, it is useful to understand how money obtains its value in the first place. So-called commodity money, such as grain or coins made from a precious metal, is valuable thanks to being made from a valuable substance. Another main type of money is fiat money, which is valuable thanks to being generally accepted as payments for goods and services somewhere, usually because of a government mandate (a fiat) requiring so (Mankiw 2009, 81-83). Other variations include representative money, which represents a claim to something valuable (e.g., gold deposit certificate), and token money, which is valuable thanks to someone pledging to redeem it for something of value.

Some virtual currencies are fiat money (e.g., virtual gold coins in a game), some are token money (e.g., Facebook Credits), and there are also virtual commodity currencies - for example, users of online hangout Habbo Hotel used virtual chairs and sofas as a currency, as these objects also had use value. The trustworthiness of all these currencies is limited by the fact that the records that make up the money are controlled by private organizations. The records might be destroyed, or the organization might recklessly issue so much new money that the value of the currency is destroyed. In contrast, material commodity currencies like actual gold coins are safer in this respect, although the value of commodities does fluctuate significantly, 
which hampers their use as money. Most national currencies today are fiat money. Fiat currencies like dollars and euros have enjoyed very stable values in the past decades, thanks to active adjustment of the money supply by central banks.

What does this mean for trustworthiness? Overall, it is probably true that virtual currencies are in practice less trustworthy today than national currencies. But this is by no means an absolute rule. Just as with digital currencies, the materials from which national fiat currencies are made of (i.e., bits, paper and metal) are almost worthless. National currencies used to be backed up by precious metals, that is, a dollar used to represent a claim to a quantity of gold, but this is no longer the case. National currencies thus have the same potential to completely lose their value as virtual currencies have. And this does happen: most recently, the Zimbabwe dollar, a "real money" according to conventional understanding, began to experience rapid inflation in 2005. The inflation exceeded 200 million percent in 2008. The whole currency was abandoned in 2009. During these four years, almost any "virtual" currency would have been a more reliable store of value - even virtual gold coins in an online game! In other words, virtual money does not fundamentally differ from real money-there is only money.

\section{Conclusions: Marginalization by Virtualization}

Through Russia's virtual economy as well as more recent examples of virtuality in the digital world, I sought to show that in the sphere of economics, the notion of virtuality tends to be associated with illusion, pretense, and even fraud. To be virtual is to be nonexistent, whereas the economy is a sphere of material provision. Thus virtuality is a vice, not a virtue. Virtuality is always established in relation to something else that represents the "real." In the case of virtual consumption, the implied real is the whole set of more established consumption practices, especially the consumption of material goods. In the case of virtual money, the quite explicitly stated real is the set of national currencies, no matter how unstable.

As the analyses in this chapter have demonstrated, when such dichotomous language is subjected to scrutiny, it turns out that the dichotomy is delusory. Virtual consumption is no less real than more conventional forms of consumption; it is arguably more tangible than the consumption of film or other media. Virtual goods are used for social signification and identity games in the same way as other goods in a consumer culture. Sales of virtual goods contribute to the national economy in the same way as their more conventional counterparts. As for virtual money, no fundamental difference can be found from highly respected national currencies, only differences of degree. Elsewhere similar real-virtual dichotomies have been argued to be equally misleading (Lehdonvirta 2010). The fact that we are nevertheless so apt to see such dichotomies around us perhaps reflects the prominence of dichotomies in the history of Western thought, from Plato's theory of forms to Cartesian mind-matter dualism. But an error is made when these metaphysical categories are imposed on the ontological reality around us.

In the introduction to this chapter, it was argued that in the sphere of economics, "virtual" is a loaded word that can be used in politics. In the previous sections, we 
saw that this "marginalization by virtualization" can occur for several reasons. Recognizing such a frivolous pursuit as virtual consumption as a valid economic activity places in question the meaningfulness of the whole consumption-centered economy. In effect, it shows that in a consumer society, all consumption is virtual. Marginalizing digital virtual consumption by placing it in an ontologically distinct category of "fake" things avoids this challenge to prevailing norms and values. Marginalization by virtualization may thus be a spontaneous reaction arising from the need to avoid cognitive dissonance.

In the case of virtual money, there is an even stronger need to maintain prevailing conceptions. As I write this, serious doubts about the viability of the common European currency, the euro, are being expressed by French president Nicolas Sarkozy. Central banks around the world are looking for alternatives to the US dollar as a reserve currency. Digital networks have made it practical to create private currencies that are used for the very same purposes as national currencies, but as of yet in much smaller scale. Despite their troubles, national currencies are still recognized as the "real money" and are therefore seen as the safest and most legitimate choice. But next-generation private digital currencies, which the distributed currency Bitcoin heralds, might in many ways turn out to be safer for the user than national currencies that risk falling prey to politics and special interests. If this turns out to be the case, then the trust placed in national currencies would hang largely on the mere idea of them being "real" money. Upholding the fictional real-virtual dichotomy would become a matter of national importance.

\section{References}

Baudrillard, J. 2002. Consumer Society. In Selected Writings, 2nd edition, edited by M. Poster, 32-59. Stanford, CA: Stanford University Press.

Belk, R. W. 2004. The Human Consequences of Consumer Culture. In Elusive Consumption, edited by K. M. Ekström and H. Brembeck, 67-86. Oxford: Berg.

Burda, M., and C. Wyplosz. 1997. Macroeconomics: A European Text. 2nd edition. New York: Oxford University Press.

Castronova, E. 2006. Virtual Worlds: A First-Hand Account of Market and Society on the Cyberian Frontier. In The Game Design Reader: A Rules of Play Anthology, edited by K. Salen and E. Zimmerman, 814-863.. Cambridge, MA: MIT Press.

Denegri-Knott, J. and M. Molesworth. 2010. Concepts and Practices of Digital Virtual Consumption. Consumption Markets and Culture 13 (2): 109-132.

Dibbell, J. 1998. My Tiny Life: Crime and Passion in a Virtual World. New York: Henry Holt.

Gaddy, C., and B. Ickes. 1998. Russia's Virtual Economy. Foreign Affairs 77: 53-67.

Gaddy, C., and B. Ickes. 2002. Russia's Virtual Economy. Washington, DC: Brookings Institution Press. 
Huhh, J. S. 2008. Culture and Business of PC Bangs in Korea. Games and Culture 3 (1): $26-37$.

Jimenez, C. 2007. The High Cost of Playing Warcraft. BBC News Online, September 24. http://news.bbc.co.uk/2/hi/technology/7007026.stm. Accessed on July 28, 2010.

Krebs, B. 2009. The Scrap Value of a Hacked PC. Washington Post Security Fix. http://voices.washingtonpost.com/securityfix/2009/05/the_scrap_value_of_a_hacked_ pc.html. Accessed March 15, 2011.

Lehdonvirta, V. 2009a. Virtual Consumption. Publications of the Turku School of Economics A-11:2009. Turku School of Economics: Turku. http://info.tse.fi/julkaisut/vk/Ae11_2009.pdf. Accessed on June 1, 2011.

Lehdonvirta, V. 2009b. Virtual Item Sales as a Revenue Model: Identifying Attributes That Drive Purchase Decisions. Electronic Commerce Research 9 (1): 97-113.

Lehdonvirta, V. 2010. Virtual Worlds Don't Exist: Questioning the Dichotomous Approach in MMO Studies. Game Studies 10 (1). http://gamestudies.org/1001/articles/lehdonvirta. Accessed June 1, 2011.

Lehdonvirta, V., and M. Ernkvist. 2011. Knowledge Map of the Virtual Economy. World Bank: Washington DC. http://www.infodev.org/en/Document.1076.pdf. Accessed June 1, 2011.

Lehdonvirta, V., and P. Virtanen. 2010. A New Frontier in Digital Content Policy: Case Studies in the Regulation of Virtual Goods and Artificial Scarcity. Policy and Internet 2 (3): 7-29.

Lehdonvirta, V., T.-A. Wilska, and M. Johnson. 2009. Virtual Consumerism: Case Habbo Hotel. Information, Communication and Society 12 (7): 1059-1079.

Lury, C. 1996. Consumer Culture. New Brunswick, NJ: Rutgers University Press.

Mankiw, N. G. 2009. Macroeconomics. 7th edition. New York: Worth Publishers.

Martin, J. 2008. Consuming Code: Use-Value, Exchange-Value, and the Role of Virtual Goods in Second Life. Journal of Virtual Worlds Research 1 (2). https://journals.tdl.org/jvwr/article/view/300/262. Accessed on May 1, 2010.

Montola, M., and J. Stenros. 2009. Pervasive Games: Theory and Design. Boston, MA: Morgan Kaufmann.

Nojima, M. 2008. 人はなぜ形のないものを買のか 仮想世界のビジネスモデル [Why do people buy immaterial goods: Virtual world business models]. Tokyo: NTT Publishing. 
Räsänen, P. 2008. The Aftermath of the ICT Revolution? Media and Communication Technology Preferences in Finland in 1999 and 2004. New Media and Society 10 (2): $225-245$.

So, S., and J. C. Westland. 2010. Red Wired: China's Internet Revolution. London: Marshall Cavendish.

Wi, J.-H. 2009. Innovation and Strategy of Online Games. London: Imperial College Press. 